Eur J Inorg Chem. 2015 September ; 2015(27): 4532-4538. doi:10.1002/ejic.201500737.

\title{
Synthesis of $\mathrm{CaTiO}_{3}$ Nanofibers with Controllable Drug-Release Kinetics
}

\author{
Qiuhong Zhang ${ }^{\mathrm{a}}$, Xiang Li ${ }^{\mathrm{a}}$, Zhaohui Ren ${ }^{\mathrm{a}}$, Gaorong Han ${ }^{\mathrm{a}}$, and Chuanbin Mao ${ }^{\mathrm{a}, \mathrm{b}}$ \\ Xiang Li: xiang.li@zju.edu.cn; Gaorong Han: hgr@zju.edu.cn; Chuanbin Mao: cbmao@ou.edu \\ aState Key Laboratory of Silicon Materials, School of Materials Science and Engineering, \\ Zhejiang University, Hangzhou 310027, P. R. China \\ bepartment of Chemistry \& Biochemistry, Stephenson Life Sciences Research Center, \\ University of Oklahoma, 101 Stephenson Parkway, Norman, Oklahoma 73019-5300, USA
}

\begin{abstract}
Calcium titanate $\left(\mathrm{CaTiO}_{3}\right)$ nanofibers with controlled microstructure were fabricated by a combination of sol-gel and electrospinning approaches. The fiber morphology has been found to rely significantly on the precursor composition. Altering the volume ratio of ethanol to acetic acid from 3.5 to 1.25 enables the morphology of the $\mathrm{CaTiO}_{3}$ nanofibers to be transformed from fibers with a circular cross section to curved ribbon-like structures. Ibuprofen (IBU) was used as a model drug to investigate the drug-loading capacity and drug-release profile of the nanofibers. It was found that the BET surface area and the pore volume decrease markedly with the utilization of F127 surfactant. The nanofibers synthesized without F127 surfactant present the highest drugloading capacity and the most sustained release kinetics. This study suggests that calcium titanate nanofibers can offer a promising platform for localized drug delivery.
\end{abstract}

\section{Keywords}

Sol-gel processes; Surfactants; Nanofibers; Electrospinning; Drug delivery

\section{Introduction}

Research on localized drug-delivery systems (LDDSs) have received burgeoning attention and have advanced rapidly in the last years due to their great potential to improve human health. Compared with conventional forms of drug dosage, LDDSs display many advantages including greater efficacy and safety, controlled and prolonged release time, and predictable therapeutic response. ${ }^{[1]}$ More recently, on the basis of the large surface area of nanofibers, the sustained drug-release kinetics, and the nontoxic nature of inorganic materials, inorganic nanofibers such as silica, ${ }^{[2]}$ bioactive glass, ${ }^{[3]}$ and hydroxyapatite ${ }^{[4]}$ have been widely investigated as candidates for modern LDDSs.

Correspondence to: Xiang Li, xiang. li@z ju. edu.cn; Gaorong Han, hgr@z ju. edu.cn; Chuanbin Mao, cbmao@ou.edu. Supporting information for this article is available on the WWW under http://dx.doi.org/10.1002/ejic.201500737. 
Calcium titanate $\left(\mathrm{CaTiO}_{3}\right)$ is a well-known bioceramic. It has been extensively used for orthopedic implants as a coating material. ${ }^{[5]} \mathrm{A} \mathrm{CaTiO}_{3}$ coating layer between titanium substrate and hydroxyapatite has been demonstrated to suppress the progression of hydroxyapatite dissolution in acidic environment caused by osteoclastic bone resorption in the body. ${ }^{[5 c, 6]} \mathrm{In}$ addition, the growth of apatite on $\mathrm{CaTiO}_{3}$ is promoted in simulated body fluids. ${ }^{[7]}$ The good stability and identified biocompatibility of $\mathrm{CaTiO}_{3}$ make it possible to extend its applications in localized drug delivery. To date, much effort has been devoted to the synthesis of $\mathrm{CaTiO}_{3}$ micro-/nanostructures by methods such as a PEG-200-assisted solvothermal procedure, ${ }^{[8]}$ the sol-gel method, ${ }^{[9]}$ and hydrothermal methods. ${ }^{[10]}$

Electrospinning is a highly versatile method for preparing fibers with dimensions down to the nanometer range. Electrospun nanofibers offer several advantages such as an extremely high surface-to-volume ratio, tunable porosity, and malleability to conform to a wide variety of sizes and shapes. ${ }^{[11]}$ With smaller pores and higher surface area than regular fibers, electrospun fibers have been successfully applied in diverse fields including tissue engineering, ${ }^{[12]}$ biosensors, ${ }^{[13]}$ filtration, ${ }^{[14]}$ wound dressings, ${ }^{[15]}$ drug delivery, ${ }^{[1 \mathrm{a}, 1 \mathrm{~b}, 16]}$ and enzyme immobilization. ${ }^{[17]}$ The nanoscale fibers are generated by the application of a strong electric field to the polymer solution. Under a strong electric field, a jet is formed and moves towards the grounded collector. On the way to the collector, the solvent evaporates, and solid fibers with diameters ranging from micrometers to nanometers precipitate on the collector. The electrospinning technique has been utilized to synthesize dense and hollow nanofibers of inorganic ceramics such as silica, ${ }^{[18]}$ bioactive glass, ${ }^{[3 \mathrm{~b}]} \mathrm{TiO}_{2},{ }^{[19]} \mathrm{SnO}_{2},{ }^{[20]} \mathrm{Al}_{2} \mathrm{O}_{3},{ }^{[21]}$ $\mathrm{In}_{2} \mathrm{O}_{3},{ }^{[22]}$ and $\mathrm{CaTiO}_{3} \cdot{ }^{[23]}$ Electrospinning has been proven to be a highly successful technique for controlling the synthesis of onedimensional nanostructures.

$\mathrm{CaTiO}_{3}$ nanofibers doped with rare earth elements have been synthesized by electrospinning for various optical applications. ${ }^{[24]}$ However, to the best of our knowledge, there is no report on electrospun $\mathrm{CaTiO}_{3}$ nanofibers for localized drug-delivery applications. Therefore, in this work we fabricated nanoscale $\mathrm{CaTiO}_{3}$ drug carriers with a method based on the electrospinning technique with subsequent heat treatment. A surfactant-assisted sol-gel method was utilized to realize the controllable synthesis of $\mathrm{CaTiO}_{3}$ nanofibers with use of Pluronic F127 as surfactant and by tuning the experimental parameters. The drug-release properties of the nanofibers were tested with ibuprofen (IBU) as a model drug.

\section{Results and Discussion}

\section{Electrospinning Synthesis Process and Phase Structure}

A schematic diagram of the electrospinning procedure of $\mathrm{CaTiO}_{3}$ nanofibers is shown in Figure 1. The setup has three components: a high-voltage power supply, a metallic needle, and a grounded collector (Figure 1a). The needle is connected to a syringe in which the precursor solution is filled. With use of a syringe pump, the solution is fed through the needle at a controllable rate. When a high voltage is applied, the pendant droplet of the precursor solution at the tip of the needle becomes highly electrified, and the induced charges get evenly distributed over the surface. As a result, under the coulombic force exerted by the external electric field and the electrostatic repulsion between the surface 
charges, the droplet is distorted to a hemispherical object and is elongated to form a conical shape known as the Taylor cone. ${ }^{[25]}$

In our study, when the applied voltage and flow rate were set at $9.8-10.6 \mathrm{kV}$ and $0.5 \mathrm{~mL} / \mathrm{h}$, respectively, a stable coneshaped electrospinning jetting mode was achieved and maintained, as captured by a speed camera (Figure 1c). Subsequently, the jet that is highly stretched and elongated under the electric field results in the formation of continuous fine fibers owing to the blending instability. ${ }^{[26]}$ When the process parameters were set outside this range, an unstable jetting mode (Figure 1b) or a multijetting mode (Figure 1d) were obtained, as a result of which non-uniform fibers were formed.

Figure 2a shows the thermogravimetric differential scanning calorimetry (TG-DSC) curves of the as-spun fibers during the calcination process by heating known quantities of fibers at a step rate of $10^{\circ} \mathrm{C} / \mathrm{min}$ in air. An increase from ambient temperature $\left(25^{\circ} \mathrm{C}\right)$ to $157.2{ }^{\circ} \mathrm{C}$, which resulted in about $9.89 \%$ weight loss in the TG curve, was accompanied with a weak broad endothermic peak at $74.58{ }^{\circ} \mathrm{C}$ due to the evaporation of residual solvent. Between 157.2 and $329.92^{\circ} \mathrm{C}$, about $69.61 \%$ weight loss was observed with two exothermic peaks at 219.01 and $312.66{ }^{\circ} \mathrm{C}$, which are attributed to the decomposition of nitrates and the degradation of polyvinylpyrrolidone (PVP). ${ }^{[27]}$ PVP degradation proceeds by two mechanisms involving both intramolecular and intermolecular transfer reactions. ${ }^{\text {[28] }}$ Between 329.92 and $550{ }^{\circ} \mathrm{C}$, there was about $4.31 \%$ weight loss with an exothermic peak at $463.15^{\circ} \mathrm{C}$, which is the result of oxidation of carbon and carbon monoxide released by the decomposition of tetrabutyltitanate and PVP. ${ }^{[27,29]}$ No further significant weight loss was observed above $600{ }^{\circ} \mathrm{C}$, indicating that the pyrolysis process was complete and the perovskite $\mathrm{CaTiO}_{3}$ phase was formed.

Figure $2 \mathrm{~b}$ shows X-ray diffraction (XRD) patterns of the fibers annealed at $700{ }^{\circ} \mathrm{C}$, welldefined diffraction peaks at (110), (111), (112), (210), (103), (022), (220), (204), (224), and (110) were detected, all of which were indexed to the orthorhombic phase of $\mathrm{CaTiO}_{3}$ (JCPDS No. 82-0228). No diffraction peaks from impurities were observed. This suggests that the fibers have crystallized in the pure orthorhombic $\mathrm{CaTiO}_{3}$ phase, which is in agreement with TGDSC results.

\section{Effect of Precursor Composition on the Fibers}

In the preparation of the $\mathrm{CaTiO}_{3}$ precursor sol, acetic acid retards the hydrolysis of titanium and stabilizes the sol for electrospinning. In addition, acetic acid can also absorb the moisture in the air, which decelerates the evaporation of the solvents and may induce a negative influence on the fine fiber morphology. Thus, it is of great importance to control the volume of acetic acid in the precursor solution. The influence of the ratio of ethanol to acetic acid on the fiber morphology was investigated experimentally, and sols with five different volume ratios of ethanol to acetic acid (1.25, 2, 3, 3.5, and 4) were prepared and electrospun, while keeping the other parameters constant. All the above as-spun $\mathrm{CaTiO}_{3}$ nanofibers were calcined at $700{ }^{\circ} \mathrm{C}$ to eliminate PVP, surfactant, and solvent. As shown in the scanning electron microscopy (SEM) images (Figure 3), $\mathrm{CaTiO}_{3}$ nanofibers obtained at different ratios presented different morphologies. When the volume ratio was set at 4 , a white precipitate formed, and the precursor solution became unstable. When the ratio was set at 3 
and 3.5, the nanofibers presented a mean diameter of about 106 and $114 \mathrm{~nm}$, respectively, and when the ratio was less than 3 , the hydrolysis of titanium butoxide was effectively hindered, ${ }^{[30]}$ and the precursor was quite stable. However, curved ribbon-like $\mathrm{CaTiO}_{3}$ was formed when the volume ratio of ethanol to acetic acid reached 1.25. The morphology of electrospun one-dimensional nanomaterials is dependent on a number of processing parameters including the type of polymer, electrical conductivity, surface tension, applied voltage, flow rate, nozzle-collector distance, and operational conditions. ${ }^{[31]}$ Under the control of these factors, evaporation of the solvent and the subsequent collapse of the fiber might be responsible for the emergence of a ribbon-like structure. ${ }^{[32]}$ Once the fiber is spun out of the nozzle during electrospinning, the solvent evaporates rapidly from the fiber, and the as-prepared fiber may completely solidify to different degrees before reaching the collector. This depends on the physical properties of the solvents. If the fibers are not completely solidified prior to reaching the collector, ribbon- like structures may form. ${ }^{[33]}$

It needs to be pointed out that acetic acid is a hygroscopic liquid with a high boiling point and ethanol is volatile at ambient temperature. When the jets are electrospun out of the nozzle, ethanol evaporates completely, while some acetic acid remains in the fiber prepared with a low volume ratio, giving rise to the formation of curved ribbonlike morphology. Thus, the volume ratio of ethanol to acetic acid plays an important role in fiber formation and structure.

The $\mathrm{CaTiO}_{3}$ nanofibers synthesized with a volume ratio of 3 were further examined by using transmission electron microscopy (TEM). The microstructural characteristics of nanofibers when different amounts of Pluronic F127, a widely used surfactant in drug-delivery systems, were used were investigated (Figure 4). Owing to the different penetration depth of electrons in different parts of the fiber body, the highly porous nature of all fibers was clearly observed. The microstructure of nanofibers prepared with F127 surfactant shows relatively more "loosened" characteristics (Figure 4b and 4e). This indicates that the F127 surfactant induces pores with increased dimensions. In addition, the polycrystalline nature of $\mathrm{CaTiO}_{3}$ nanofibers is confirmed from the selected area electron diffraction patterns (the insets of Figure $4 \mathrm{~b}$ and $4 \mathrm{e}$ ). The HRTEM images, shown in Figure $4 \mathrm{c}$ and $4 \mathrm{f}$, present a large scale of neatly arranged lattice fringes with no obvious defects. The $d$-spacing values are 0.382 and $0.270 \mathrm{~nm}$, corresponding to the (110) and (112) crystal facets of the orthorhombic $\mathrm{CaTiO}_{3}$ phase, respectively. Those results indicate that all fibers are of fine crystallinity, which agrees well with the findings from XRD studies.

The formation mechanism of porous $\mathrm{CaTiO}_{3}$ nanofibers is demonstrated in Figure 5. The precursor solution is composed of a metal salt solution, PVP, and F127 surfactant. PVP was used to adjust the viscoelastic behavior and make the sol suitable for further electrospinning. Pluronic F127 is an amphiphilic block copolymer, which has a large solubility difference between its hydrophilic and hydrophobic segments. Such copolymer molecules selfassemble into micelles, a core-shell architecture, where hydrophobic segments are segregated from the exterior solution to form an inner core surrounded by a shell of hydrophilic segments. ${ }^{[34]}$ The F127 micelles can exist in the as-spun fibers. Under hightemperature sintering, $\mathrm{CaTiO}_{3}$ nanofibers with porous structure are obtained, because the 
F127 micelle template and PVP molecules vanish. Thus, $\mathrm{CaTiO}_{3}$ nanofibers prepared with or without F127 surfactant have different porous microstructures.

The unique microstructure characteristics of $\mathrm{CaTiO}_{3}$ nanofibers facilitate the potential of this material as a localized drug-delivery system. To further investigate the porosity of $\mathrm{CaTiO}_{3}$ nanofibers, the specific surface area and pore characteristics of fibers were examined by using $\mathrm{N}_{2}$ adsorption/desorption measurements. As shown in Figure 6, $\mathrm{CaTiO}_{3}$ nanofibers prepared with or without F127 surfactant both showed representative IV-type isotherms, which are characteristics of typical porous materials. The specific surface area and pore volume of the fibers, calculated using the Brunauer-Emmett-Teller (BET) and BarrettJoyner-Halenda (BJH) methods, are summarized in Table 1. The fibers synthesized with F127 have a BET surface area of about $18.1 \mathrm{~m}^{2} / \mathrm{g}$ and a pore volume of about $0.071 \mathrm{~cm}^{3} / \mathrm{g}$, while those synthesized without the surfactant were found to show a higher BET surface area (ca. $30.7 \mathrm{~m}^{2} / \mathrm{g}$ ) and a larger pore volume (ca. $0.119 \mathrm{~cm}^{3} / \mathrm{g}$ ). The reason for such a difference is the formation of F127 micelles, as discussed above. This result matches those reported previously. [2a,34a,35]

\section{Drug Loading and Release}

Figure 7 shows the FTIR spectra of $\mathrm{CaTiO}_{3}$ nanofibers, IBU-loaded $\mathrm{CaTiO}_{3}$ nanofibers, and the pure IBU drug. For the $\mathrm{CaTiO}_{3}$ nanofibers, strong absorption peaks at about 445 and 556 $\mathrm{cm}^{-1}$ are attributed to the bending mode of Ti-O. ${ }^{[36]}$ The weak bands assigned to the hydroxyl absorption $\left(3432 \mathrm{~cm}^{-1}\right)$ and the $\mathrm{O}-\mathrm{H}$ vibrations of $\mathrm{H}_{2} \mathrm{O}\left(1635 \mathrm{~cm}^{-1}\right)$ indicate the presence of hydroxyl groups and $\mathrm{H}_{2} \mathrm{O}$ molecules on the surface of $\mathrm{CaTiO}_{3}$ nanofibers, which is important for the attachment IBU molecules. When $\mathrm{CaTiO}_{3}$ nanofibers were loaded with IBU molecules, typical characteristic peaks assignable to $-\mathrm{COOH}$ vibration at about 1720 $\mathrm{cm}^{-1}$ and $\mathrm{C}-\mathrm{H}_{X}$ bonds at about 2862 and $2960 \mathrm{~cm}^{-1}$ were clearly observed, except for a slight decrease in intensity compared with that of pure IBU drug. Furthermore, absorption bands, which could be assigned to the quaternary carbon atom at about 1460 and $1512 \mathrm{~cm}^{-1}$ and to the tertiary carbon atom at $1329 \mathrm{~cm}^{-1}$ arising from the introduced IBU molecules, were also observed, confirming that IBU drug was successfully loaded on the $\mathrm{CaTiO}_{3}$ nanofibers.

The absorbance of IBU in phosphate-buffered saline (PBS) solution is shown in Figure S1a. Obviously, the maximum absorbance occurs at a characteristic wavelength of $222 \mathrm{~nm}$.

Therefore, the in vitro examination of IBU release by UV/Vis spectroscopy was carried out at this wavelength. The relationship between absorbance at $222 \mathrm{~nm}$ and IBU concentration is demonstrated in Figure S1b. When the IBU concentration ranges from 0.010 to 0.025 $\mathrm{mg} / \mathrm{mL}$, the absorbance at $222 \mathrm{~nm}$ shows good linearity with the IBU concentration, and the correlation coefficient reaches $99.408 \%$. The IBU concentration in the release medium can be calculated by the equation:

$$
A_{222}=31.402 C_{\mathrm{IBU}}+0.1488
$$


where $A_{222}$ is the absorbance at $222 \mathrm{~nm}$ and $C_{\mathrm{IBU}}$ is the concentration of IBU in the collected sample. Hence, the drug-loading capacity and cumulative drug release can be calculated by means of the above calibration curve equation.

In the drug-loading procedure, the IBU molecules can be adsorbed onto the surface of the highly porous $\mathrm{CaTiO}_{3}$ nanofibers. The drug-loading capacities of the IBU-loaded $\mathrm{CaTiO}_{3}$ nanofibers prepared with and without F127 surfactant were calculated to be about 24.5 and $43.7 \mathrm{wt} .-\%$, respectively. It is interesting to find that the amount of drug loaded on the fibers prepared without F127 surfactant is nearly double that loaded on the fibers prepared with surfactant. Moreover, the BET surface area and pore volume of the fibers prepared without surfactant are also nearly two times those of the fibers prepared with the surfactant, which indicates a correlation between the drug-loading capacity and the BET surface area and pore volume of the porous materials.

During the drug-release process in PBS solution, accompanied by fluid diffusion into the pores of the nanofibers, IBU molecules are liberated from the fibers and released into the fluid by a diffusion-controlled mechanism. Figure 8 shows the cumulative drug-release profiles as a function of release time for IBU-loaded $\mathrm{CaTiO}_{3}$ nanofibers. Rather different release behavior was observed for the two types of $\mathrm{CaTiO}_{3}$ nanofibers. A typical drugrelease phenomenon consists of two stages, including an initial fast-release stage, dominated by the rapid leaching of free IBU molecules from the outer surfaces of the fibers, and a relatively slow subsequent release stage, ascribed to drug liberation from the porous structure of the fibers. The $\mathrm{CaTiO}_{3}$ nanofibers synthesized without F127 surfactant present a dramatically sustained drug-release rate due to their reduced pore dimensions and increased BET surface area. About $28 \mathrm{wt} .-\%$ of IBU drug is liberated from the nanofibers within the initial $2 \mathrm{~h}$, and about $66 \mathrm{wt} .-\%$ of the total IBU drug is released after $48 \mathrm{~h}$. In contrast, for the $\mathrm{CaTiO}_{3}$ nanofibers with low BET surface area and large pore dimensions, the amount of released IBU drug reaches about 48 and 66 wt.- $\%$ within the initial 2 and $8 \mathrm{~h}$, respectively. Therefore, the drug-loading capacity and the drug-release behavior have been successfully manipulated by the synthesis of $\mathrm{CaTiO}_{3}$ nanofibers with varied microstructure. Our findings suggest another promising localized drug-delivery system for a variety of pharmaceutical applications such as localized tumor therapy, which require sustained release to reduce the significant side effects of the drugs.

\section{Conclusions}

A range of $\mathrm{CaTiO}_{3}$ nanofibers with controlled microstructure were synthesized by a combination of the sol-gel and electrospinning methods. By tuning the volume ratio of ethanol to acetic acid, the morphology of $\mathrm{CaTiO}_{3}$ nanofibers can be transformed from nanofibers with a circular cross section to ribbon-like fibers. The formation of the ribbonlike structure is ascribed to inadequate solvent evaporation from the precursor fiber before it reaches the collector. Amphiphilic block copolymer Pluronic F127 was used to vary the pore structure of $\mathrm{CaTiO}_{3}$ nanofibers through self-assembly of $\mathrm{F} 127$ micelles and subsequent calcination. Thus the drug-loading capacity and drug-release behavior of the $\mathrm{CaTiO}_{3}$ nanofibers were manipulated by altering their microstructure. As a result of their high surface area, large pore volume, and small pore dimensions, the $\mathrm{CaTiO}_{3}$ nanofibers 
synthesized without F127 present the highest drug-loading capacity and most sustained drug-release kinetics. The study has suggested that such $\mathrm{CaTiO}_{3}$ nanofibers with unique mesoporous microstructure can serve as a promising localized drug-delivery system for modern biomedical applications.

\section{Experimental Section}

\section{Reagents and Materials}

Calcium nitrate tetrahydrate $\left[\mathrm{Ca}\left(\mathrm{NO}_{3}\right)_{2} \cdot 4 \mathrm{H}_{2} \mathrm{O}, 99 \%\right]$, titanium butoxide $\left[\mathrm{Ti}\left(\mathrm{OC}_{4} \mathrm{H}_{9}\right)_{4}\right.$, $>98.0 \%$ ], polyvinylpyrrolidone (PVP, $M_{\mathrm{W}}=1,300,000$, Aladdin), Pluronic F127 $\left(\mathrm{EO}_{106} \mathrm{PO}_{70} \mathrm{EO}_{106}, M_{\mathrm{W}}=12600\right.$, Sigma-Aldrich), Ibuprofen (IBU, 99\%, Nanjing Chemical Regent Co., Ltd.), acetic acid $\left(\mathrm{C}_{2} \mathrm{H}_{4} \mathrm{O}_{2}\right.$, A.R.), ethanol $\left(\mathrm{C}_{2} \mathrm{H}_{6} \mathrm{O}\right.$, A.R.), $N, N-$ dimethylformamide $\left(\mathrm{C}_{3} \mathrm{H}_{7} \mathrm{NO}\right.$, A.R.), and phosphate-buffered saline (PBS, $\mathrm{pH}=7.4$, Sinopharm Chemical Reagent Co., Ltd) were used as received without further purification.

Fabrication of $\mathrm{CaTiO}_{3}$ Nanofibers-Briefly, $\mathrm{Ti}\left(\mathrm{OC}_{4} \mathrm{H}_{9}\right)_{4}(\mathrm{ca} .0 .82 \mathrm{~g})$ and $\mathrm{Ca}\left(\mathrm{NO}_{3}\right)_{2} \cdot 4 \mathrm{H}_{2} \mathrm{O}$ (ca. $0.56 \mathrm{~g}$ ) were dissolved in a mixed solution $(9 \mathrm{~mL})$ containing acetic acid and ethanol (volume ratio of ethanol to acetic acid 1.25, 2, 3, 3.5, and 4) with magnetic stirring. Then surfactant (Pluronic F127, 1.26 wt.-\%) and polyvinylpyrrolidone (PVP, 3.25 wt.-\%) were added with $N, N$-dimethylformamide solution and stirred for another $6 \mathrm{~h}$ to form spinnable precursor sols.

The electrospinning sol was fed into the conducting nozzle ( $2 \mathrm{~mm}$ inner diameter) by using an infusion pump (KDS-100, KD Scientific, USA) at a constant flow rate of $0.5 \mathrm{~mL} / \mathrm{h}$. The distance and voltage applied between the needle tip and the collector were set at $15 \mathrm{~cm}$ and $10 \mathrm{kV}$ (PS/FC30P04.0-22, Glassman High voltage Inc., USA), respectively. As-spun fibers were dried overnight at $80{ }^{\circ} \mathrm{C}$ and calcined in air at $700{ }^{\circ} \mathrm{C}$ for $2 \mathrm{~h}$, with a heating rate of $2{ }^{\circ} \mathrm{C} / \mathrm{min}$.

\section{Characterization}

The thermal behavior, crystal structure, morphology, and microstructure were investigated by using TG-DSC (DSCQ1000, AT, USA, air atmosphere), XRD (X'PertPRO MPD, Netherlands, using $\mathrm{Cu}-K_{\mathrm{a}}$ radiation, $\lambda=0.1540598 \mathrm{~nm}$ ), SEM (FE SEM, Hitachi SU-70, Japan), and TEM (Philips TecnaiF20 S-TWIN, Netherlands), respectively. The specific surface area and pore size distribution were determined by $\mathrm{N}_{2}$ adsorption/desorption analysis at liquid nitrogen temperature (77 K) by using a Coulter OMNISORP-100 apparatus. The FTIR spectra were recorded with a Perkin-Elmer 580B infrared spectrophotometer on $\mathrm{KBr}$ pellets (Tensor 27, Bruker, Germany). UV/Vis absorption values were measured with a TU-1810 spectrophotometer.

Drug Loading and Release-IBU-release measurements were carried out by UV/Vis absorption spectroscopy. The absorbance values were measured at a characteristic wavelength of $222 \mathrm{~nm}$, at which the IBU-release medium shows the maximum absorbance. A calibration curve was drawn by plotting absorbance vs. IBU concentration. 
In the drug-loading procedure, $\mathrm{CaTiO}_{3}$ nanofibers $(300 \mathrm{mg})$ were suspended in a hexane solution of IBU $(40 \mathrm{mg} / \mathrm{mL}, 50 \mathrm{~mL})$ at ambient temperature and stirred for $24 \mathrm{~h}$ to induce the diffusion of the drug into the pores. Then, the nanofibers were collected by centrifugation and washed with hexane to remove the IBU adsorbed on the outer surface. The filtrate $(1 \mathrm{~mL})$ was collected and diluted for the measurement of drug-loading capacity by UV/Vis spectroscopy at a wavelength of $222 \mathrm{~nm}$.

In vitro drug release was investigated after IBU-loaded $\mathrm{CaTiO}_{3}$ nanofibers were dried overnight at $60{ }^{\circ} \mathrm{C}$. IBU-loaded $\mathrm{CaTiO}_{3}$ nanofibers $(200 \mathrm{mg})$ were immersed in the release medium PBS with gentle stirring at $37^{\circ} \mathrm{C}$. At each selected time interval, an aliquot $(1 \mathrm{~mL})$ was collected and immediately replaced with an equal volume of fresh PBS. The samples collected were diluted and analyzed by UV/Vis spectroscopy at a wavelength of $222 \mathrm{~nm}$.

\section{Supplementary Material}

Refer to Web version on PubMed Central for supplementary material.

\section{Acknowledgments}

This work was financially supported by the National Nature Science Foundation of China (No. 51232006), the "Qianjiang" Talent Program of Zhejiang Province (2013R10037), and the Nature Science Foundation of Zhejiang Province (LY15E020005). C. M. would like to thank for the financial support from National Institutes of Health (EB015190) and National Science Foundation (CMMI-1234957).

\section{References}

1. a) Hou ZY, Li XJ, Li CX, Dai YL, Ma PA, Zhang X, Kang XJ, Cheng ZY, Lin J. Langmuir. 2013; 29:9473-9482. [PubMed: 23855606] b) Hong Y, Chen X, Jing X, Fan H, Guo B, Gu Z, Zhang X. Adv. Mater. 2010; 22:754-758. [PubMed: 20217784] c) Vallet-Regi M, Ramila A, del Real RP, Perez-Pariente J. Chem. Mater. 2001; 13:308-311.

2. a) Chen Z, Li X, He H, Ren Z, Liu Y, Wang J, Li Z, Shen G, Han G. Colloids Surf. B. 2012; 95:274-278.b) Xu Z, Liu S, Kang Y, Wang M. Nanoscale. 2015; 7:5859-5868. [PubMed: 25757484]

3. a) Huang S, Kang X, Cheng Z, Ma P, Jia Y, Lin J. J. Colloid Interface Sci. 2012; 387:285-291. [PubMed: 22964090] b) Hong Y, Chen X, Jing X, Fan H, Gu Z, Zhang X. Adv. Funct. Mater. 2010; 20:1503-1510.c) Li Y, Li B, Xu G, Ahmad Z, Ren Z, Dong Y, Li X, Weng W, Han G. Colloids Surf. B. 2014; 122:785-791.

4. Hou Z, Yang P, Lian H, Wang L, Zhang C, Li C, Chai R, Cheng Z, Lin J. Chem. Eur. J. 2009; 15:6973-6982. [PubMed: 19496099]

5. a) Huang P, Xu KW, Han Y. Mater. Lett. 2005; 59:185- 189.b) Tang H, Wang F. Mater. Lett. 2013; 93:427-430.c) Wiff JP, Fuenzalida VM, Arias JL, Fernandez MS. Mater. Lett. 2007; 61:2739-2743.

6. a) Kaciulis GMS, Pandolfi L, Cavalli M, Gnappi G, Montenero A. Appl. Surf. Sci. 1999; 151:1-5.b) Holliday S, Stanishevsky A. Surf. Coat. Technol. 2004; 188:741-744.

7. a) Asami K, Saito K, Ohtsu N, Nagata S, Hanawa T. Surf. Interface Anal. 2003; 35:483-488.b) Webster TJ, Ergun C, Doremus RH, Lanford WA. J. Biomed. Mater. Res., Part A. 2003; 67:975980 .

8. Yang XF, Fu JX, Jin CJ, Chen JA, Liang CL, Wu MM, Zhou WZ. J. Am. Chem. Soc. 2010; 132:14279-14287. [PubMed: 20843080]

9. Ruzimuradov O, Hasegawa G, Kanamori K, Nakanishi K. J. Am. Ceram. Soc. 2011; 94:3335-3339.

10. Yu DB, Zhang JH, Wang F, Zhao MH, Du K, Shu SW, Zou JW, Wang Y. Cryst. Growth Des. 2013; 13:3138-3143.

11. Bhardwaj N, Kundu SC. Biotechnol. Adv. 2010; 28:325-347. [PubMed: 20100560] 
12. a) Jeffries EM, Allen RA, Gao J, Pesce M, Wang YD. Acta Biomaterials. 2015; 18:30-39.b) Ru CH, Wang FL, Pang M, Sun LN, Chen RH, Sun Y. ACS Appl. Mater. Interfaces. 2015; 7:1087210877. [PubMed: 25941905] c) Thunberg J, Kalogeropoulos T, Kuzmenko V, Hagg D, Johannesson S, Westman G, Gatenholm P. Cellulose. 2015; 22:1459-1467.

13. a) Promphet N, Rattanarat P, Rangkupan R, Chailapakul O, Rodthongkum N. Sensor Actuat. BChem. 2015; 207:526-534.b) Zhang PP, Zhao XN, Ji YC, Ouyang ZF, Wen X, Li JF, Su ZQ, Wei G. J. Mater. Chem. B. 2015; 3:2487- 2496.

14. a) Wang Z, Zhao CC, Pan ZJ. J. Colloid Interface Sci. 2015; 441:121-129. [PubMed: 25499733] b) Li XQ, Wang N, Fan G, Yu JY, Gao J, Sun G, Ding B. J. Colloid Interface Sci. 2015; 439:12- 20. [PubMed: 25463170]

15. a) Lowe A, Bills J, Verma R, Lavery L, Davis K, Balkus KJ. Acta BioMater. 2015; 13:121-130. [PubMed: 25463501] b) Zhao R, Li X, Sun BL, Tong Y, Jiang ZQ, Wang C. Rsc Adv. 2015; 5:16940-16949.

16. Hou Z, Li C, Ma P, Li G, Cheng Z, Peng C, Yang D, Yang P, Lin J. Adv. Funct. Mater. 2011; 21:2356-2365.

17. a) Xu R, Si YF, Li FT, Zhang BR. Environ. Sci. Pollut. Res. Int. 2015; 22:3838-3846. [PubMed: 25269844] b) Tang C, Saquing CD, Morton SW, Glatz BN, Kelly RM, Khan SA. ACS Appl. Mater. Interfaces. 2014; 6:11899-11906. [PubMed: 25058141]

18. Wang W, Zhou J, Zhang S, Song J, Duan H, Zhou M, Gong C, Bao Z, Lu B, Li X, Lan W, Xie E. J. Mater. Chem. 2010; 20:9068.

19. a) Tang K, Yu Y, Mu X, van Aken PA, Maier J. Electrochem. Commun. 2013; 28:54-57.b) Li D, Xia YN. Nano Lett. 2003; 3:555-560.

20. Li WQ, Ma SY, Luo J, Mao YZ, Cheng L, Gengzang DJ, Xu XL, Yan SH. Mater. Lett. 2014; 132:338-341.

21. Zhang PP, Chen DR, Jiao XL. Eur. J. Inorg. Chem. 2012:4167-4173.

22. Li ZP, Fan YJ, Zhan JH. Eur. J. Inorg. Chem. 2010:3348- 3353.

23. Zhang Q, Li Y, Ren Z, Ahmad Z, Li X, Han G. Mater. Lett. 2015; 152:82-85.

24. a) Peng C, Hou Z, Zhang C, Li G, Lian H, Cheng Z, Lin J. Opt. Express. 2010; 18:7543-7553. [PubMed: 20389776] b) Dong GP, Xiao XD, Zhang LL, Ma ZJ, Bao X, Peng MY, Zhang QY, Qiu JR. J. Mater. Chem. 2011; 21:2194-2203.

25. a) Frenot A, Chronakis IS. Curr. Opin. Colloid Interface Sci. 2003; 8:64-75.b) Reneker DH, Chun I. Nanotechnology. 1996; 7:216-223.c) Shin YM, Hohman MM, Brenner MP, Rutledge GC. Appl. Phys. Lett. 2001; 78:1149-1151.d) Reneker DH, Yarin AL, Fong H, Koombhongse S. J. Appl. Phys. 2000; 87:4531-4547.

26. a) Yarin AL, Koombhongse S, Reneker DH. J. Appl. Phys. 2001; 90:4836-4846.b) Shin YM, Hohman MM, Brenner MP, Rutledge GC. Polymer. 2001; 42:9955-9967.

27. Wang LL, Liu XM, Hou ZY, Li CX, Yang PP, Cheng ZY, Lian HZ, Lin J. J. Phys. Chem. C. 2008; 112:18882- 18888 .

28. Dish SJAMA. Polym. Degrad. Stab. 1998; 60:253-256.

29. Peng C, Hou Z, Zhang C, Li G, Lian H, Cheng Z, Lin J. Opt. Express. 2010; 18:7543-7553. [PubMed: 20389776]

30. Fu Y, Jin Z, Ni Y, Du H, Wang T. Thin Solid Films. 2009; 517:5634-5640.

31. Greiner A, Wendorff JH. Angew. Chem. Int. Ed. 2007; 46:5670-5703.Angew. Chem. 2007; 119:5770.

32. a) Li D, Xia YN. Adv. Mater. 2004; 16:1151-1170.b) Guo X, Szoka FC. Acc. Chem. Res. 2003; 36:335-341. [PubMed: 12755643] c) Uhrich KE, Cannizzaro SM, Langer RS, Shakesheff KM. Chem. Rev. 1999; 99:3181-3198. [PubMed: 11749514] d) Kataoka K, Harada A, Nagasaki Y. Adv. Drug Delivery Rev. 2001; 47:113-131.

33. Sill TJ, von Recum HA. Biomaterials. 2008; 29:1989-2006. [PubMed: 18281090]

34. a) Saha J, De G. Chem. Commun. 2013; 49:6322-6324.b) Zhao W, Su YL, Li C, Shi Q, Ning X, Jiang ZY. J. Membr. Sci. 2008; 318:405-412. 
35. a) Grosso D, Soler-Illia GJdAA, Crepaldi EL, Cagnol F, Sinturel C, Bourgeois A, Brunet-Bruneau A, Amenitsch H, Albouy PA, Sanchez Cm. Chem. Mater. 2003; 15:4562-4570.b) Yang PD, Zhao DY, Chmelka BF, Stucky GD. Chem. Mater. 1998; 10:2033-2036.

36. a) Maensiri S, Nuansing W, Klinkaewnarong J, Laokul P, Khemprasit J. J. Colloid Interface Sci. 2006; 297:578-583. [PubMed: 16332372] b) Yang HK, Chung JW, Raju GSR, Moon BK, Choi BC, Jeong JH, Kim JH. Appl. Surf. Sci. 2009; 255:5062- 5066.c) Shivaram M, Nagabhushana H, Sharma SC, Prashantha SC, Daruka Prasad B, Dhananjaya N, Hari Krishna R, Nagabhushana BM, Shivakumara C, Chakradhar RP. Spectrochim. Acta Part A. 2014; 128:891-901. 

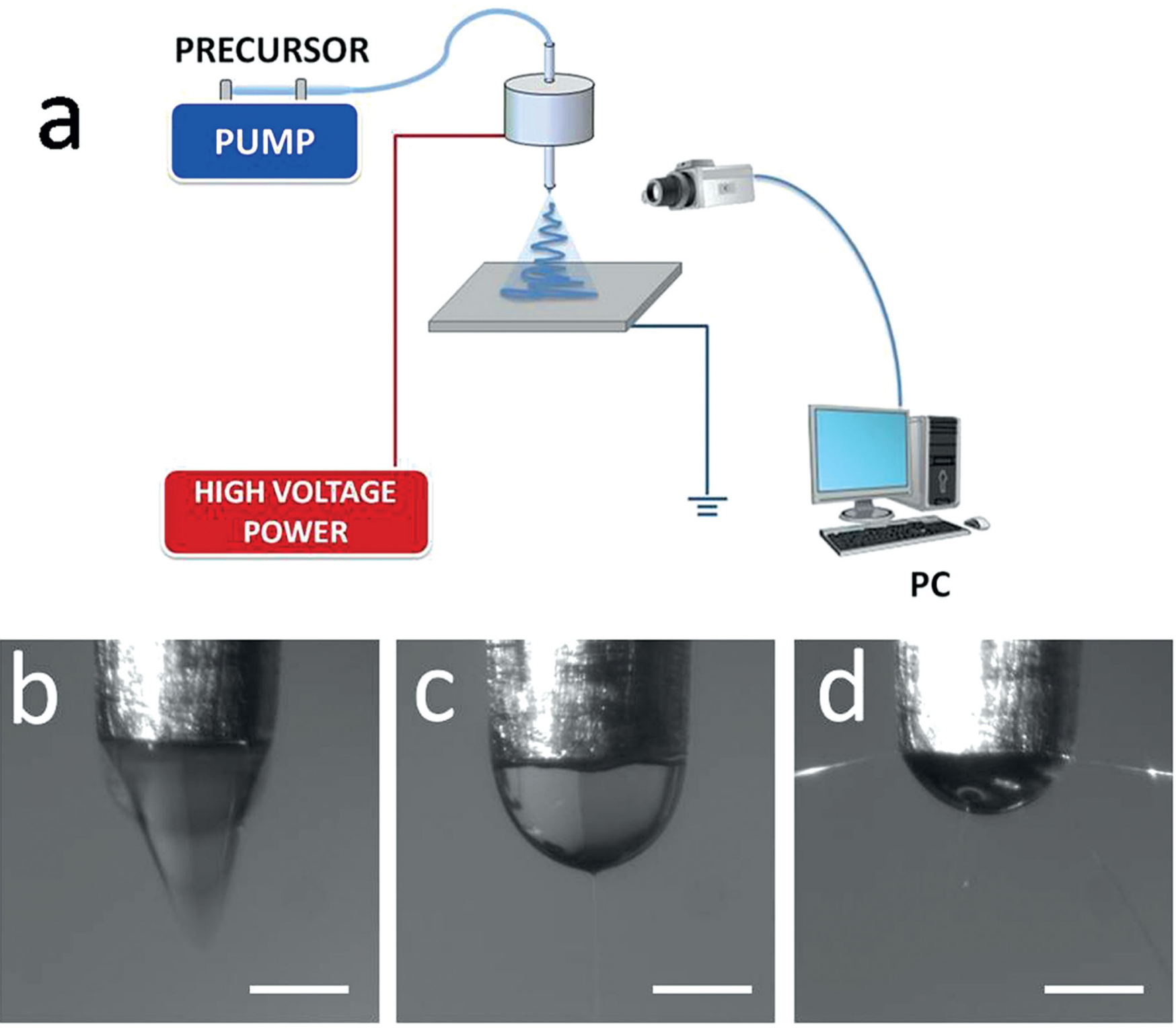

Figure 1.

(a) Schematic diagram of electrospinning setup. (b-d) The high-speed camera image of the jet during electrospinning at different voltages. The scale bar is $1 \mathrm{~mm}$. 

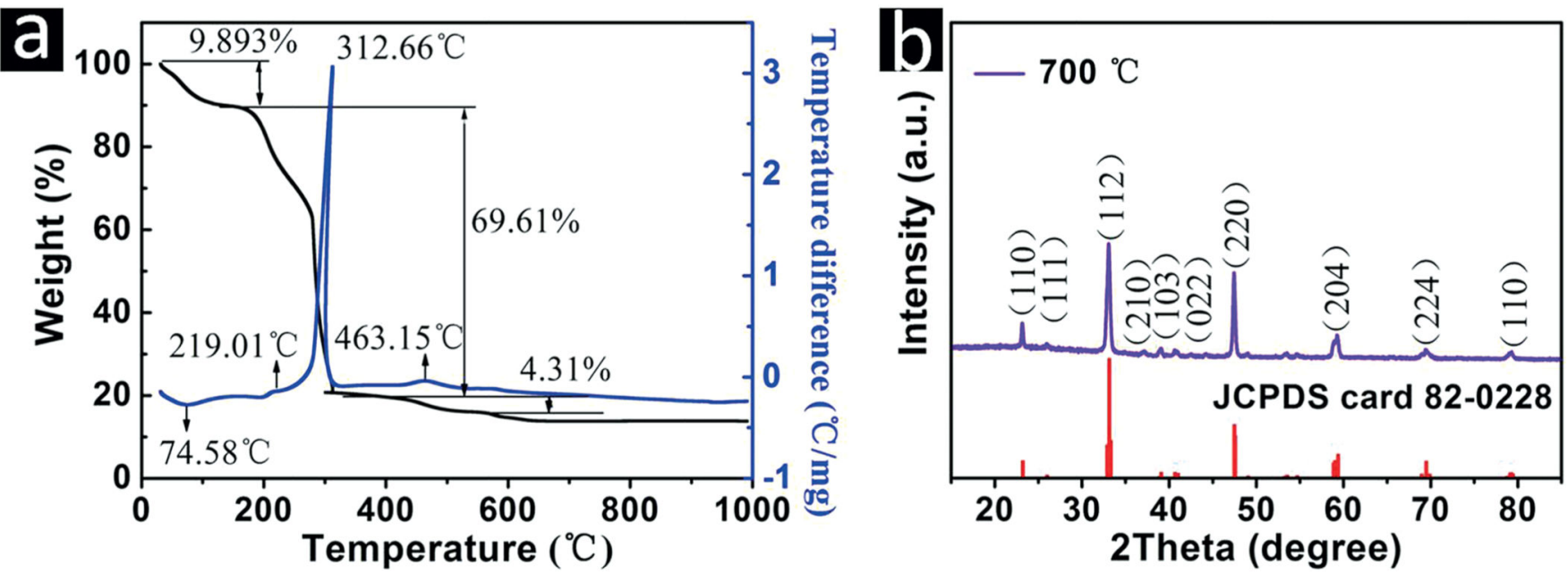

Figure 2.

(a) TG-DSC curves of as-spun $\mathrm{CaTiO}_{3}$ nanofibers and (b) XRD patterns of $\mathrm{CaTiO}_{3}$ nanofibers annealed at $700{ }^{\circ} \mathrm{C}$. 

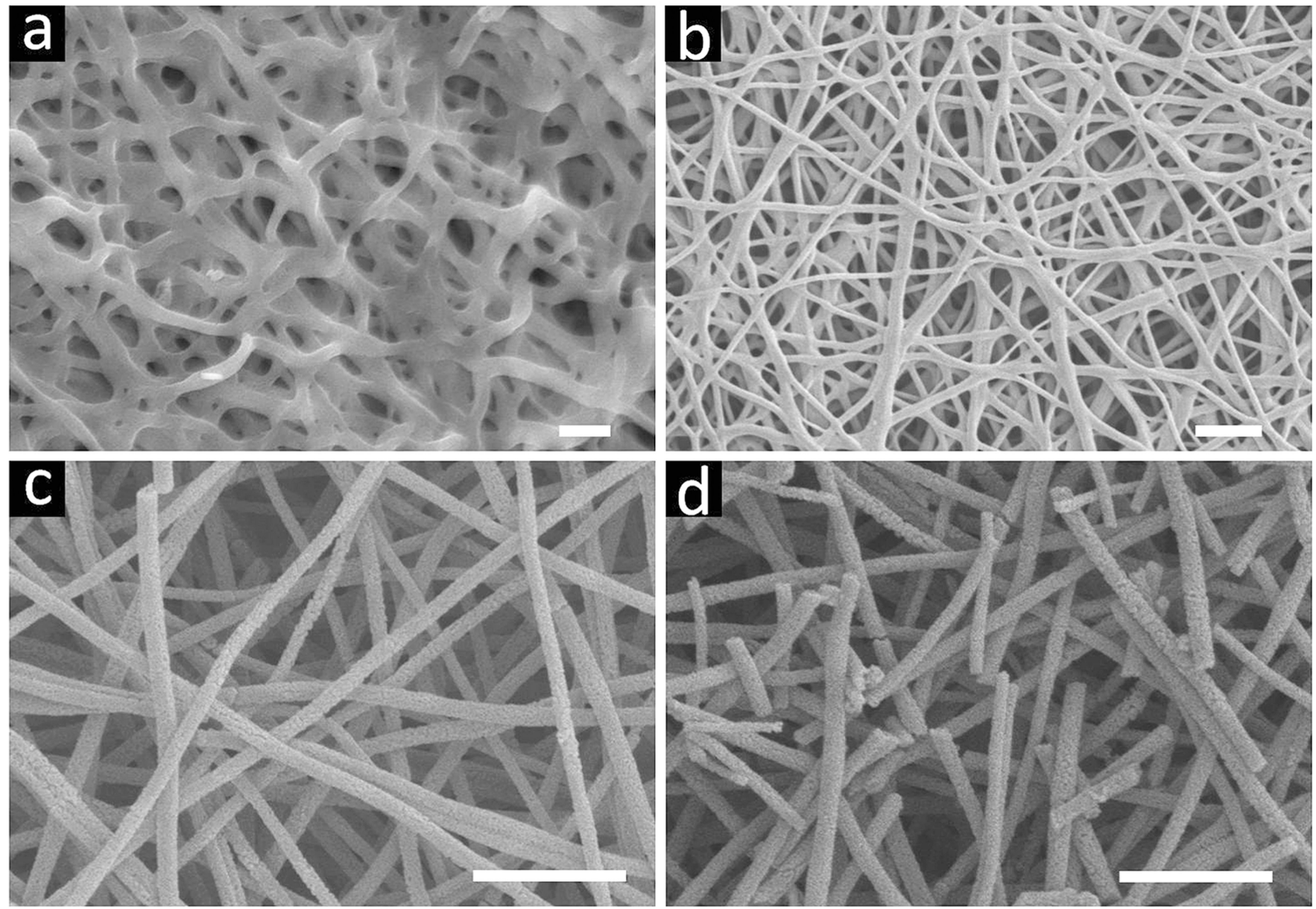

Figure 3.

SEM images of $\mathrm{CaTiO}_{3}$ nanofibers obtained at various volume ratios of ethanol to acetic acid: (a) 1.25 , (b) 2 , (c) 3 , and (d) 3.5 . $\mathrm{CaTiO}_{3}$ nanofibers in (d) seem to be cut during the strong sonication procedure while the sample was collected prior to examination by SEM. The scale bar is $1 \mu \mathrm{m}$. 

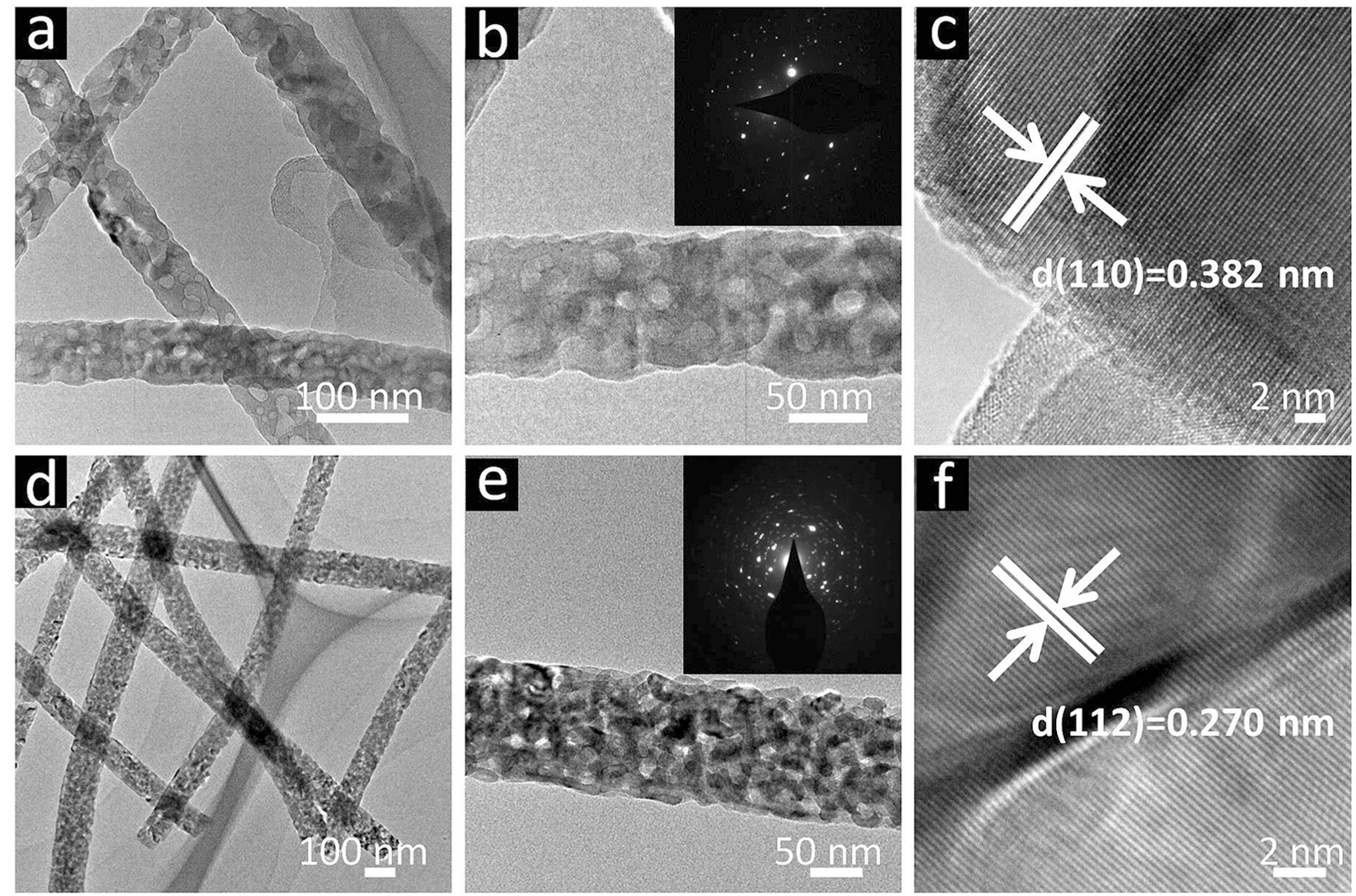

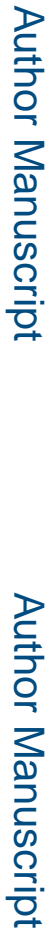

Figure 4.

TEM and HRTEM images of $\mathrm{CaTiO}_{3}$ nanofibers obtained with (a-c) and without (d-f) F127 surfactant. Insets: SAED pattern of a single nanofiber. 


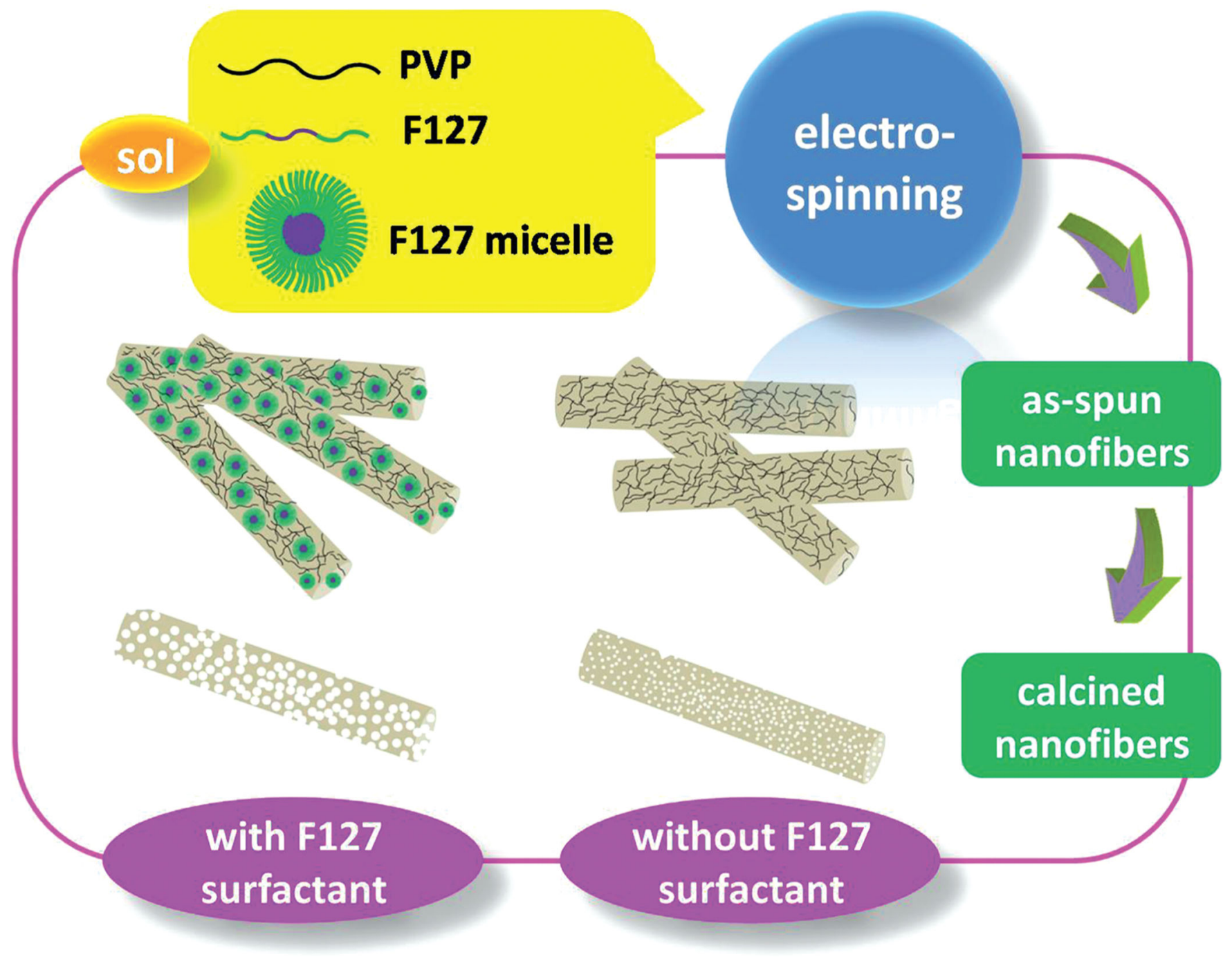

Figure 5.

Illustration of the formation process of porous $\mathrm{CaTiO}_{3}$ nanofibers. 


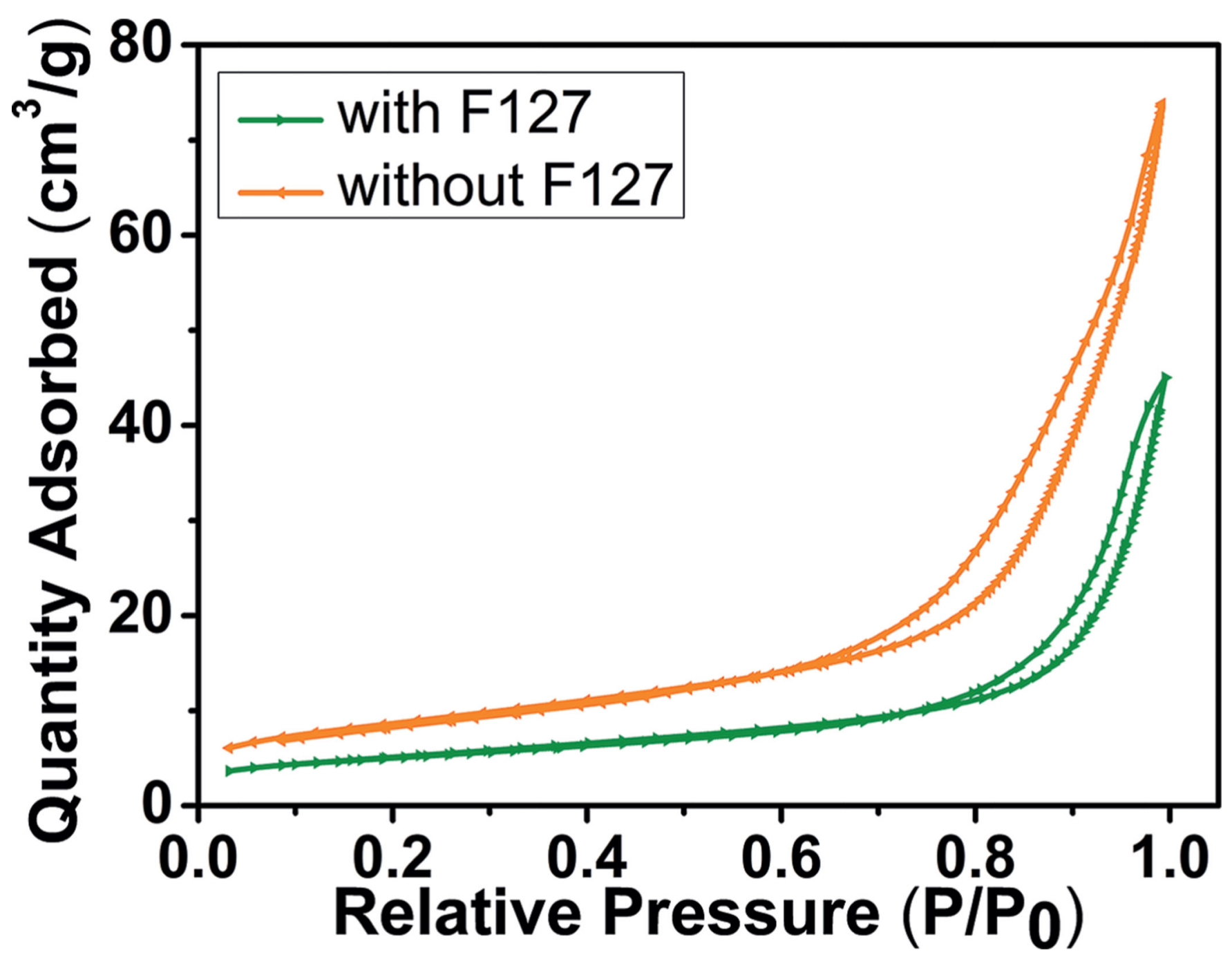

Figure 6.

$\mathrm{N}_{2}$ adsorption/desorption isotherm of $\mathrm{CaTiO}_{3}$ nanofibers. 

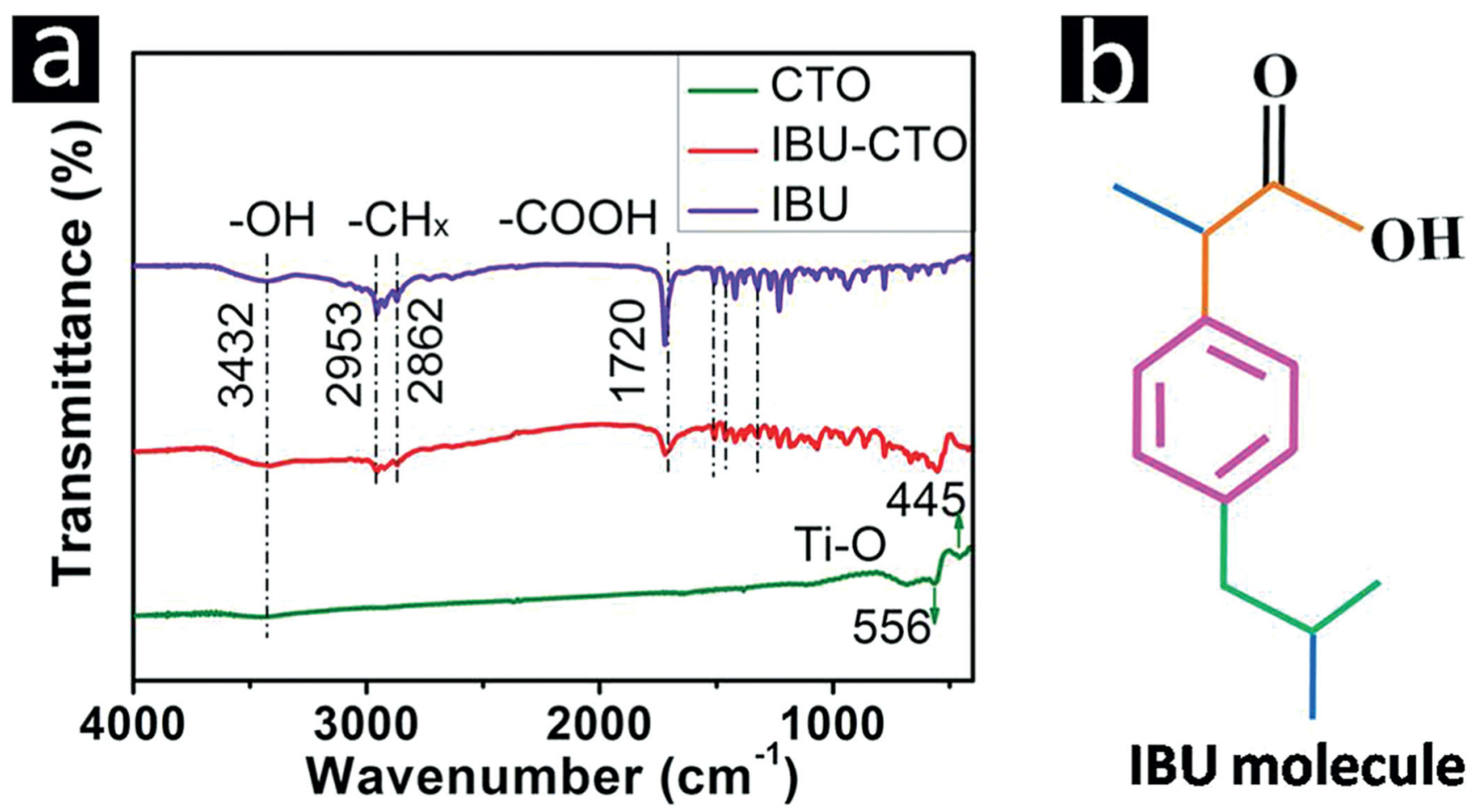

Figure 7.

(a) FTIR spectra of $\mathrm{CaTiO}_{3}$ nanofibers, IBU-loaded $\mathrm{CaTiO}_{3}$ nanofibers, and pure IBU. (b) The molecular structure of IBU. 


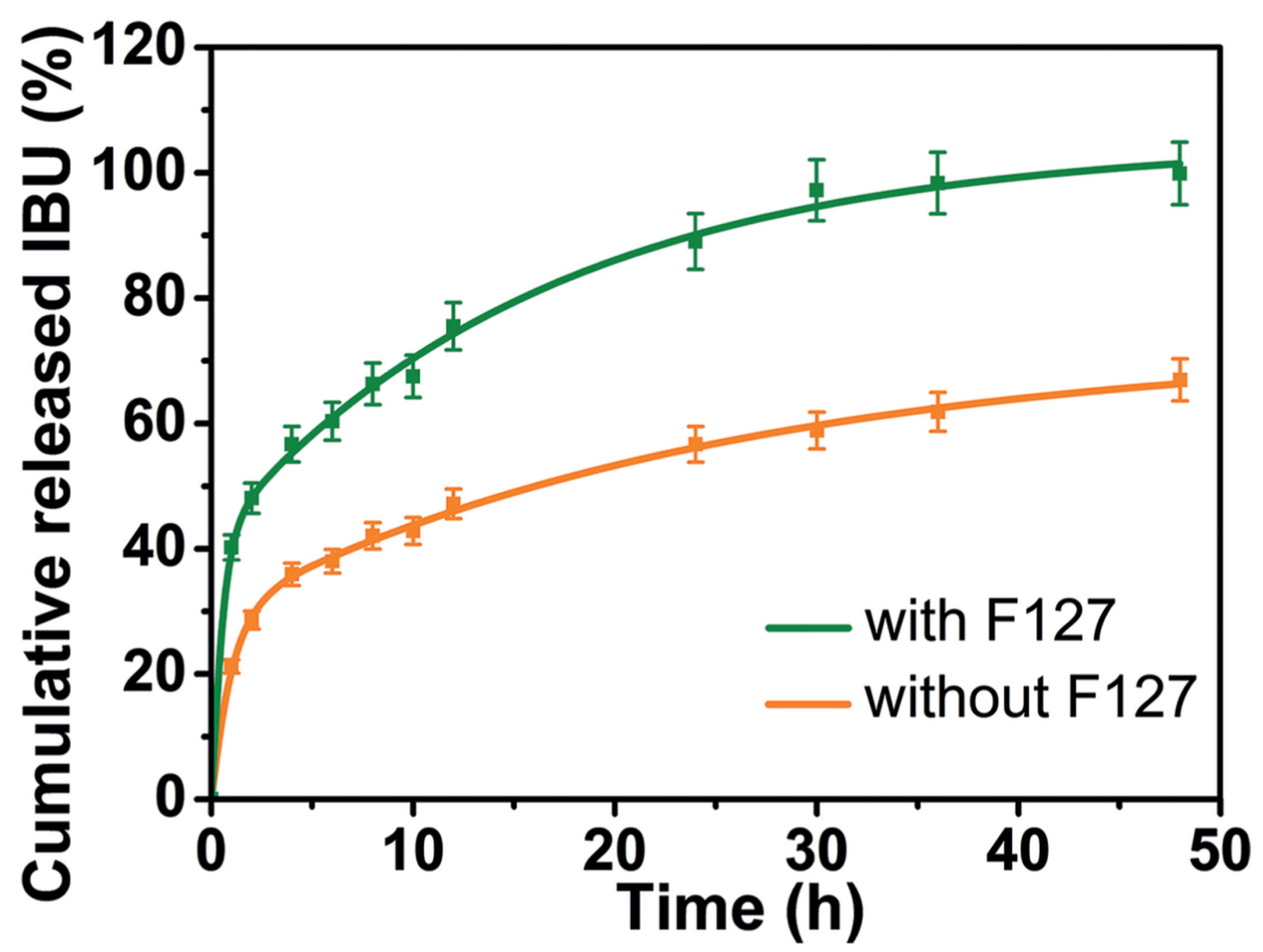

Figure 8.

Cumulative drug-release profiles as a function of release time for IBU-loaded $\mathrm{CaTiO}_{3}$ nanofibers. 


\section{Table 1}

The BET surface area, pore volume, and drug-loading capacity of $\mathrm{CaTiO}_{3}$ nanofibers.

\begin{tabular}{llll}
\hline Sample & $\begin{array}{l}\text { BET surface area } \\
\left(\mathbf{m}^{2} / \mathbf{g}\right)\end{array}$ & $\begin{array}{l}\text { Pore volume } \\
\left(\mathbf{c m}^{\mathbf{3}} \mathbf{g}\right)\end{array}$ & $\begin{array}{l}\text { Drug-loading capacity } \\
(\mathbf{w t . - \%})\end{array}$ \\
\hline Without F127 & 30.7 & 0.119 & 43.7 \\
With F127 & 18.1 & 0.071 & 24.5 \\
\hline
\end{tabular}

